\title{
FAT EMBOLISM SYNDROME CASE IN A WOMAN PRESENTING WITH MULTIPLE INJURIES FOLLOWING A TRAFFIC ACCIDENT SUCCESSFULLY TREATED USING INTERDISCIPLINARY APPROACH , CASE REPORT
}

\author{
Szymon Bialka ${ }^{1} \oplus$, Adam Ubych ${ }^{2}{ }^{\circ}$, Jacek Smereka ${ }^{3}$, \\ Tomasz Byrczek ${ }^{4}{ }^{\oplus}$, Krzysztof Szaniewski $^{5}$, Lukasz Szarpak ${ }^{6}$ \\ ${ }^{1}$ Department of Anaesthesiology, Intensive Care and Emergency Medicine, School of Medicine with Division of Dentistry in Zabrze, \\ Medical University of Silesia, Zabrze, Poland \\ ${ }^{2}$ Centre of Didactics and Medical Simulation, Medical University of Silesia, Katowice, Poland \\ ${ }^{3}$ Department of Emergency Medical Service and Laboratory of Experimental Medicine and Innovative Technology, \\ Wroclaw Medical University, Poland \\ ${ }^{4}$ Department of Emergency Medicine, Medical University of Silesia, Poland \\ ${ }^{5}$ Department of Vascular Surgery Trauma Centre Hospital N05 District of Silesia, Poland \\ ${ }^{6}$ Medical Faculty of Lazarski University, Warsaw, Poland
}

KEY WORDS: fat embolism syndrome; multiple injury; interdisciplinary therapeutic approach; case report

Disaster Emerg Med J 2020; 5(1): 57-59

\section{BACKGROUND}

Trauma is among the main causes of death among people aged under 30 years. A potential complication of extensive injuries is an episode of fat embolism [1], also referred to as fat embolism syndrome (FES) in literature [2]. The main causes of fat embolism include long bone and pelvic fractures. Depending on the severity of injuries, their character, and the number of fractures, the frequency of this complication ranges from $0.25 \%$ to $8.0 \%$ [3]. Symptoms of fat embolism may also develop after elective orthopaedic surgery, removal of subcutaneous fat tissue, multiple rib fractures, acute pancreatitis, or parenteral nutrition with fat-containing products [4].

Two mechanisms are considered to lead to the development of clinical signs. At the first stage, lung arterioles are mechanically closed by fat globules released into veins. At the later stage, mediators are released as a result of hydrolysis of the fatty embolism material and the release of a large amount of free fatty acids. Massive free fatty acids release under the influence of increased adrenergic stimulation explains FES in patients without injury $[3,5]$.

\section{Chief complaints}

\section{CASE REPORT}

A 44-year-old woman presenting with multiple injuries following a traffic accident (hit by a car) was transported by a medical emergency team to a hospital emergency department.

\section{History of present illness}

Patient's symptoms started after a traffic accident.

\section{History of past illness}

The patient had a free previous medical history.

\section{Physical examination}

At the time of hospital admission, the patient was unconscious, unresponsive; Glasgow Coma Scale: 4 points; respiratory failure. The patient was intubated and mechanically ventilated with FiO2 1.0; oxygen saturation $90 \%$, presented circulatory insufficiency; heart rate: 110/min, blood pressure: $90 / 50 \mathrm{~mm} \mathrm{Hg}$, pulse on radial artery undetectable. The trauma examination showed a wound in the parietal region and chest bruising. 


\section{Imaging examinations}

The focused assessment with sonography in trauma found no fluid in the peritoneal or pleural cavity. Computed tomography revealed a paracerebral haematoma up to $6 \mathrm{~mm}$ wide along the right frontal lobe and a rupture fissure in the left frontal bone passing through the upper wall of the left orbit. A small amount of fluid was visible in the left maxillary sinus, as well as haematoma and emphysema of soft tissues of the head in the right parietal region. Additionally, numerous fractures of ribs, transverse processes of thoracic vertebrae, and right scapula were confirmed.

\section{Final diagnosis}

The final diagnosis of the presented case is fat embolism syndrome.

\section{Treatment}

After orthopaedic surgical treatment, the patient was transferred to an intensive care unit owing to her severe condition. Mechanical ventilation was continued with $\mathrm{FiO} 2$ 1.0, SpO2 92\%. In the following hours, a decreased ratio of $\mathrm{PaO} 2 / \mathrm{FiO} 2<250 \mathrm{~mm}$ $\mathrm{Hg}$ was observed in the arterial blood gas test. Circulatory insufficiency was present with noradrenaline infusion in the dose of $0.25 \mu \mathrm{g} / \mathrm{kg} / \mathrm{min}$. Fever up to $38.5^{\circ} \mathrm{C}$. Follow-up laboratory tests confirmed anaemia (HGB: 8.9 g/dl, HCT: 26.6\%) and thrombocytopenia $($ PLT $117 \times 103 / \mu l)$. Symptoms of oliguria with renal failure were found; creatinine: $1.2 \mathrm{mg} / \mathrm{dl}, \mathrm{GFR}$ : $70 \mathrm{ml} / \mathrm{min} / 1.73 \mathrm{~m} 2$.

On the second day of hospital treatment, abdominal computed tomography was performed which raised suspicion of spleen injury and revealed left iliac vein thrombosis with suspicion of fat embolism (Fig. 1).

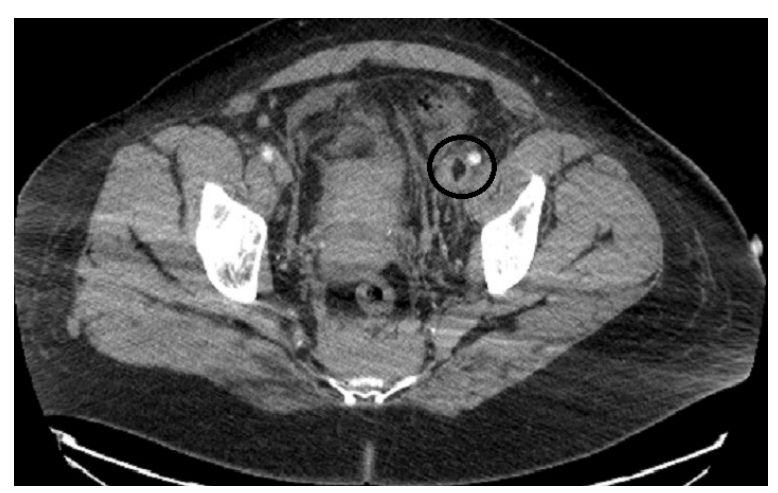

FIGURE 1. Abdominal computed tomography with contrast. Left common iliac vein widened to $16 \mathrm{~mm}$, without visible contrasting. Left external iliac vein widened to $22 \mathrm{~mm}$, without flow maintained, with a $12 \times 10 \mathrm{~mm}$ area of fat density visible in its light. The picture probably corresponds to fat embolism
On surgical consultation, the patient was disqualified from laparotomy owing to her severe condition and ambiguous diagnostic tests results. On the basis of the clinical picture confirmed by the results of radiological studies, the diagnosis of fat embolism was made. In order to stabilize the clinical condition, symptomatic treatment was implemented which included filling the vascular bed with human albumin solution $(200 \mathrm{mg} / \mathrm{ml})$ with a simultaneous norepinephrine infusion (under control of haemodynamic parameters measured by the Pulse Contour Cardiac Output technology), mechanical ventilation, supply of unfractionated heparin and methylprednisolone. Metamizole, paracetamol, and physical cooling were applied to prevent body temperature rise above $38^{\circ} \mathrm{C}$. The implementation of the above treatment resulted in an improvement of the patient's general condition.

The patient was surgically consulted again for the procedure of filter insertion into the inferior vena cava. On stabilization of the ventilation and circulatory parameters, 14 days after the accident, the patient was transferred to a vascular surgery ward for preventive insertion of a vascular filter (Fig. 2).

Before leaving the intensive care unit, the patient informed about the rules of publication and consented to the description of her case in the scientific journal.

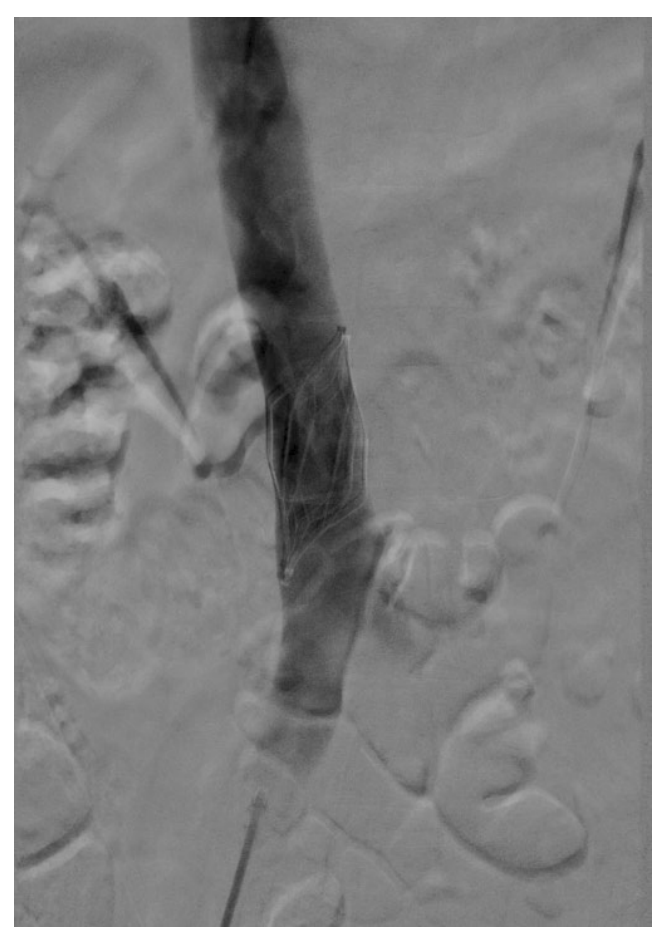

FIGURE 2. X-ray with contrast. Endovascular filter inserted to the inferior vena cava 


\begin{tabular}{|c|c|}
\hline $\begin{array}{l}\text { Large clinical } \\
\text { criteria }\end{array}$ & $\begin{array}{l}\text { Hemorrhagic skin bleeding } \\
\text { Hypoxia: PaO2 < } 60 \mathrm{~mm} \mathrm{Hg} \\
\text { Central nervous system disorders } \\
\text { Pulmonary edema }\end{array}$ \\
\hline $\begin{array}{l}\text { Small clinical } \\
\text { criteria }\end{array}$ & $\begin{array}{l}\text { Tachycardia }>120 / \text { min } \\
\text { Fever }>38^{\circ} \mathrm{C} \\
\text { Changes in the retina: ecchymosis, droplets } \\
\text { of fat in vessels } \\
\text { Icterus } \\
\text { Renal symptoms: anuria or oliguria }\end{array}$ \\
\hline $\begin{array}{l}\text { Laboratory } \\
\text { criteria }\end{array}$ & $\begin{array}{l}\text { Thrombocytopenia } \\
\text { Anemia } \\
\text { High erythrocyte sedimentation rate } \\
\text { Fatty macroglobulinemia }\end{array}$ \\
\hline
\end{tabular}

\section{DISCUSSION}

Most of the possible clinical signs are non-specific. Initially, an asymptomatic phase (12-72 hours) occurs $[6,7]$, followed by a progression of symptoms. FES causes central nervous system symptoms (headache, confusion, unconsciousness, convulsions, stupor, or brain oedema) [8], skin symptoms (reddish-brown petechiae visible on the upper body skin and conjunctiva), and a number of non-specific symptoms, such as tachycardia, fever, retinal haemorrhages, exudative oedema, jaundice, or lipiduria [1]. The triad of clinical signs including gas exchange disorders in the lungs, central nervous system disorders, and bloody petechiae on the skin makes FES diagnosis much easier. However, the final diagnosis is based on meeting one large criterion, four small criteria, and one laboratory criterion in accordance with Gurd's assumptions (Tab. 1) [9].

\section{CONCLUSION}

Proper diagnosis of FES in patients with severe trauma can be significantly impeded in everyday clinical practice. This is due to the fact that the symptoms typical of FES (such as gas exchange disorders, central nervous system disorders, bloody petechiae on the skin, laboratory abnormalities) commonly occur in injured patients, masking FES presentation.

Precise knowledge of the pathomechanism and clinical presentation of FES seems indispensable in the approach of an interdisciplinary therapeutic team. A quick correct diagnosis is crucial to improve treatment results. Access to laboratory and imaging tests considerably facilitates the diagnostic process, which should be followed by optimal therapeutic management. The lack of a golden standard of treatment necessitates a flexible and interdisciplinary therapeutic approach.

Source(s) of financial support: No declare.

Acknowledgements: None.

Conflict of interests: None.

\section{REFERENCES}

1. Stein PD, Yaekoub AY, Matta F, et al. Fat embolism syndrome. Am J Med Sci. 2008; 336(6): 472-477, doi: 10.1097/MAJ.0b013e318172f5d2, indexed in Pubmed: 19092320.

2. Berlot $G$, Bussani $R$, Shafiei $V$, et al. Fulminant Cerebral Fat Embolism: Case Description and Review of the Literature. Case Rep Crit Care. 2018; 2018: 7813175, doi: 10.1155/2018/7813175, indexed in Pubmed: 30105101.

3. Newbigin $\mathrm{K}$, Souza CA, Torres C, et al. Fat embolism syndrome: Stateof-the-art review focused on pulmonary imaging findings. Respir Med. 2016; 113: 93-100, doi: 10.1016/j.rmed.2016.01.018, indexed in Pubmed: 26895808.

4. Zhibin Z, Peng S, Fang C. Fat embolism following a liposuction procedure. Neurol India. 2018; 66(4): 1206-1207, doi: 10.4103/00283886.236965, indexed in Pubmed: 30038132.

5. Akhtar S. Fat embolism. Anesthesiol Clin. 2009; 27(3): 533-550, doi: 10.1016/j.anclin.2009.07.018, indexed in Pubmed: 19825491.

6. Saigal $R$, Mittal $M$, Kansal $A$, et al. Fat embolism syndrome. J Assoc Physicians India. 2008; 56: 245-249, indexed in Pubmed: 18702388.

7. Eriksson EA, Rickey J, Leon SM, et al. Fat embolism in pediatric patients: an autopsy evaluation of incidence and etiology. J Crit Care. 2015; 30(1): 221.e1-221.e5, doi: 10.1016/j.jcrc.2014.09.008, indexed in Pubmed: 25306239.

8. Blokhuis TJ, Pape HC, Frölke JP. Timing of definitive fixation of major long bone fractures: Can fat embolism syndrome be prevented? Injury. 2017; 48 Suppl 1: S3-S6, doi: 10.1016/j.injury.2017.04.015, indexed in Pubmed: 28449860.

9. Gurd $A R$, Wilson RI, Gurd $A R$, et al. Fat-embolism syndrome. Lancet. 1972; 2(7770): 231-232, doi: 10.1016/s0140-6736(72)91669-8, indexed in Pubmed: 4114239. 